\title{
Uma Avaliação Preliminar da Relação Entre Desempenho Acadêmico e Tipo Psicológico em Acadêmicos de Sistemas de Informação
}

\author{
Giovanni Stroppa Faquin', Matheus Henrique da Silva Muniz', Maria Luiza Furtuoso \\ Falci $^{2}$, Marco Antônio Pereira Araújo ${ }^{1,2}$ \\ ${ }^{1}$ Instituto Federal do Sudeste de Minas Gerais (IF Sudeste MG) - Campus Juiz de Fora - \\ Núcleo de Informática \\ ${ }^{2}$ Programa de Pós-Graduação em Ciência da Computação - Universidade Federal de Juiz de \\ Fora (UFJF). \\ giostroppa@gmail.com, \{matheushenrique-sm1995, marialuiza.ff\}@hotmail.com, \\ marco.araujodifsudestemg.edu.br
}

\begin{abstract}
A professional in Information Systems (IS) is defined by a set of diverse skills and depth in a practical application field. Companies and institutions linked to academia and governments are searching for a better alignment between the skills developed by students of higher education and those desired by the labor market. This article presents results of an experimental study applied to students of IS that has mapped his academic performance and psychological profile. The study aims to understand how the comprehension of individual psychological characteristics can be used by students for both self-knowledge and a better academic performance and by educators for a more effective engagement of students.
\end{abstract}

Resumo. Um profissional em Sistemas de Informação (SI) é definido por um conjunto de habilidades diversificado e aprofundado em um campo de aplicação prática. Empresas e instituições ligadas à academia e governos buscam maior alinhamento entre as habilidades desenvolvidas por alunos e aquelas desejadas pelo mercado de trabalho. Este artigo apresenta resultados de um estudo experimental aplicado a alunos do curso de SI que mapeou o desempenho acadêmico e a relação com o perfil psicológico dos alunos. O objetivo é compreender como características psicológicas individuais podem ser utilizadas por estudantes para o autoconhecimento e ser utilizado por educadores para um engajamento mais efetivo dos alunos nos cursos.

\section{Introdução}

Um profissional em Sistemas de Informação é definido por um conjunto de habilidades ao mesmo tempo diversificado e aprofundado em um campo de aplicação prática. Essas habilidades variam desde as estritamente técnicas até outras emocionais e intelectuais como a capacidade de trabalho em equipe e de se autoavaliar, além de fluência na comunicação oral e escrita. Instituições ligadas à academia e a agências governamentais, bem como atores da indústria de tecnologia, buscam caminhos para um melhor alinhamento e diálogo entre as

FAQUIN, G. S.; MUNIZ, M. H. S.; FALCI, M. L. F.; ARAÚJO, M. A. P.

Uma Avaliação Preliminar da Relação Entre Desempenho Acadêmico e Tipo Psicológico em Acadêmicos de Sistemas de Informação

iSys | Revista Brasileira de Sistemas de Informação, Rio de Janeiro, vol. 10, No. 2, pp. 138-152, 2017 
habilidades desejadas pelo mercado de trabalho e aquelas desenvolvidas pelos acadêmicos em cursos superiores. Entre os resultados práticos desse esforço cita-se a definição de diretrizes curriculares no Brasil [Brasil 2014] e de um corpo de conhecimento mínimo que caracterize e unifique cursos de computação no mundo [Ardis 2014] [Topi 2010 e 2015].

Paralelamente, estudos identificam situações que agravam o problema da formação de mão-de-obra em tecnologia no Brasil. Seja por trazer do ensino médio uma baixa proficiência em disciplinas da área de conhecimento de matemáticas, pela pressão para inserção rápida ao mercado de trabalho ou por desconhecimento sobre o corpo de conhecimento relativo à computação, identifica-se no país uma alta taxa de evasão no ensino superior: em média, apenas $31 \%$ dos alunos concluem seus cursos, segundo dados da Brasscom para o período 2006-2013 em cursos de tecnologia e comunicação, com um mínimo de 25\% de concluintes alcançado em 2008 [Amorim 2015]. Na Figura 1 observa-se como, a despeito da variação no número de inscritos em processos seletivos na área de computação, no número de vagas disponibilizadas e no número de ingressantes nos cursos superiores, o número de concluintes permanece estável para o período entre 2006 e 2013 para o caso brasileiro.

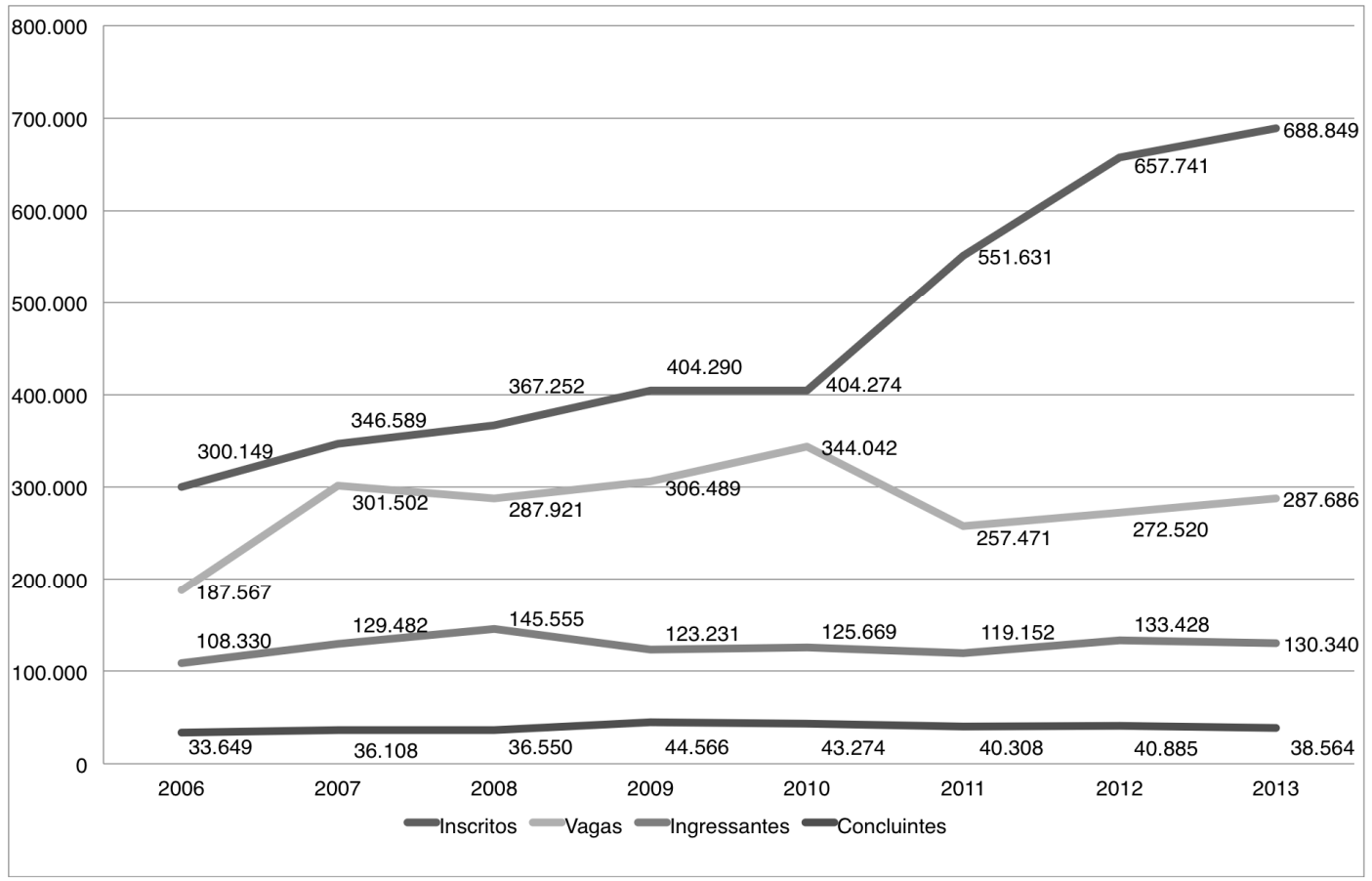

Figura 1. Evolução de Inscritos, Vagas Disponibilizadas, Alunos Ingressantes e Concluintes em Cursos da Área de Tecnologia e Comunicação (Adaptado de [Amorim 2015])

Observa-se que, em relação a 2013, o número de alunos concluintes em 2006 é $87 \%$ do total, o número de alunos ingressantes em 2006 é $83 \%$ do total, o total de vagas disponibilizadas em 2006 é 65\% do total. Por fim, o número de inscritos em processos seletivos no ano de 2006 é 43\% do alcançado em 2013. Dessa forma, o número de concluintes não aumenta na mesma proporção em que são oferecidas mais vagas ou há maior interesse na área.

Na Tabela 1 observa-se a evolução do mercado de trabalho em tecnologia da 
informação e comunicação. A sólida tendência de aumento no número de postos de trabalho disponíveis é acompanhada por um crescimento persistente no déficit de mão-de-obra. Considerando-se a variação entre os anos de 2012 e 2013 como exemplo, observa-se um crescimento positivo de contratações: 38.425 novos postos ocupados. Nesse mesmo período, entretanto, observa-se um crescimento na demanda por mão-de-obra da ordem de 64.338 novas vagas, restando cerca de 26.000 vagas de trabalho não ocupadas a alimentar o déficit. O ensino superior é capaz de suprir, na melhor das hipóteses, com cerca de 59\% dos novos postos de trabalho. Essa capacidade tende a ser menor na realidade pois formandos em cursos superiores na área de computação competem no mercado de trabalho com profissionais de nível técnico, de superior em outras áreas e com aqueles que não possuem nenhum diploma. O déficit é persistente no crescimento, agravando o quadro de carência de mão-de-obra no setor de software e serviços de tecnologia da informação.

Tabela 1. Evolução de profissionais contratados, demanda e déficit de mão-de-obra (Adaptado de [Softex, 2013])

\begin{tabular}{|c|c|c|c|}
\hline Ano & Contratados & Demanda & Déficit \\
\hline 2006 & 388.541 & 399.649 & 11.108 \\
\hline 2007 & 413.327 & 437.081 & 23.754 \\
\hline 2008 & 439.941 & 478.044 & 38.102 \\
\hline 2009 & 468.541 & 522.872 & 54.331 \\
\hline 2010 & 499.297 & 571.934 & 72.637 \\
\hline 2011 & 532.397 & 625.633 & 93.236 \\
\hline 2012 & 568.047 & 684.409 & 116.362 \\
\hline 2013 & 606.472 & 748.747 & 142.275 \\
\hline
\end{tabular}

É necessário que instituições de ensino, estudantes e educadores preocupem-se não apenas com a transmissão e retenção de conteúdo curricular, mas que também estejam atentos com a forma como as habilidades são exploradas e incorporadas pelos alunos em sala de aula e como podem auxiliar na criação de um maior vínculo entre o aluno e o curso superior. Como uma contribuição que propõe mitigar a evolução desse déficit e buscar um aproveitamento mais eficaz do capital humano e dos recursos de infraestrutura em educação disponíveis, o presente trabalho apresenta resultados de um estudo experimental aplicado a alunos do curso de Bacharelado em Sistemas de Informação em uma instituição de ensino superior pública que mapeou conexões entre seus desempenhos acadêmicos e seus perfis psicológicos. O estudo tem por objetivo compreender como o entendimento de características psicológicas individuais pode ser utilizado por estudantes para o autoconhecimento, o desenvolvimento de habilidades de forma mais efetiva e adequada aos seus perfis psicológicos e para o incremento de seus desempenhos acadêmicos. Por educadores, como uma ferramenta de auxílio ao incremento de um engajamento mais efetivo dos alunos nos cursos de graduação.

Ao considerar aspectos humanos, e não apenas os puramente técnicos ou formais, na investigação de fatores de impacto sobre o desempenho humano, o presente trabalho busca contribuir para um campo de estudo interdisciplinar em crescimento, receptivo a pesquisas focadas em investigar como a compreensão de dimensões cognitivas e psicológicas, de ordem pessoal ou social, pode contribuir para o enriquecimento da área de Sistemas de Informação. Um motivador para o presente estudo é a sólida tendência observada de uma acelerada mudança e crescente flexibilização de perfis e funções profissionais resultante do 
surgimento de novas tecnologias e modelos de negócio [Brasscom 2016]. A tradicional e compartimentada forma de entendimento do ciclo de vida de um software vem sendo progressivamente suplantada, onde aplicável, pela necessidade de uma maior e melhor integração entre todas as partes envolvidas no ciclo de vida de um processo de negócio. Essa postura busca valorizar uma abordagem mais holística a respeito de Sistemas de Informação e desenvolver novas tecnologias de auxílio a uma melhor integração do conhecimento entre as partes envolvidas [Erol 2010].

\section{Habilidades e Perfis Psicológicos}

As habilidades requeridas de um profissional de Sistemas de Informação são amplas. Esse conjunto plural de habilidades consta em diretrizes curriculares criadas tanto no Brasil quanto no exterior. Contribuem ainda para a definição de habilidades as recomendações contidas em manuais de Engenharia de Software e aquelas derivadas de boas práticas de desenvolvimento, como as descritas nos princípios da agilidade. Adicionalmente, a velocidade com que novas tecnologias são disponibilizadas dificulta a delimitação e padronização de funções profissionais. Nesse sentido, a hipótese adotada neste estudo é que a introdução dos alunos à discussão sobre o seu próprio perfil psicológico e o das pessoas em seu entorno, bem como a apresentação ao debate sobre as habilidades requeridas de um profissional, pode auxiliar o estudante a compreender melhor seu potencial, explorar disposições e comportamentos que lhe sejam mais familiares, identificar com mais clareza habilidades em que possua menor desempenho e aquelas em que atinja uma maior proficiência, bem como preparar o estudante para lidar com a diversidade e valorizá-la.

A teoria de perfis psicológicos foi primeiramente proposta na década de 1920 pelo psicólogo suíço Carl Frederich Jung. Ao se voltar para o estudo da mente humana adulta, investiu em um detalhado estudo de tipos comportamentais psicológicos [Jung 1976]. Jung apresenta uma diferenciação essencial entre dois tipos psicológicos ou disposições típicas da consciência: o extrovertido e o introvertido. Essas duas disposições ou atitudes se articulam com quatro funções psicológicas de orientação fundamentais: pensar e sentir (racional) e perceber e intuir (irracional). Jung cria, assim, oito combinações, ou tipos psicológicos, através dos quais são detalhadas características que buscam descrever, para cada indivíduo, a forma mais natural de sua disposição. Uma vez observado qual seu tipo natural, formas de descontentamento, perturbação, opressão e violência sofridas pelo indivíduo em sua singularidade psíquica tornam-se mais nítidas. Analogamente, pressões externas ou internas podem levar um indivíduo à falsificação de seu tipo, levando-o a desenvolver neuroses, só lhe sendo possível uma cura ao se restabelecer a disposição que naturalmente lhe conviria.

Na década de 1950, Katharine C. Briggs e Isabel Briggs Myers estudaram a obra do psicanalista, expandiram-na e basearam-se nela para apresentar um instrumento, o questionário MBTI (Myers-Briggs Type Indicator), como forma de avaliar, no indivíduo, a tipologia criada por Jung. O objetivo das pesquisadoras era organizar os tipos propostos por Jung de forma a elaborar uma forma eficaz de descrever e explicar diferenças consistentes entre personalidades e que uma avaliação desse tipo pudesse ter uma aplicação prática. Atualmente, o questionário MBTI é largamente aplicado em educação, desenvolvimento de carreira, comportamento organizacional, desempenho de grupo, coaching, psicoterapia com indivíduos, casais e famílias, entre outros [Quenk 2009].

Ressalta-se que tanto a teoria jungiana de tipos psicológicos como a avaliação 
Myers-Briggs não defendem uma rotulação estática e definitiva do indivíduo. A um indivíduo é perfeitamente normal que transite por entre diferentes tipos psicológicos conforme as configurações conjunturais em que se insere. Segundo Jung, esse trânsito é um instrumento de compensação existente nos seres humanos e ocorre entre consciente e inconsciente. Trata-se de uma capacidade que objetiva, num indivíduo saudável, o equilíbrio psíquico. O que é colocado pela teoria é a predisposição existente em cada indivíduo à predominância de um dos tipos e sua permanência nele na maior parte do tempo. De forma semelhante, como indicado anteriormente, problemas podem surgir quando um indivíduo é levado a permanecer, de forma falseada, em uma configuração psicológica diversa à sua disposição natural ou momentânea. Segundo Jung, "o homem não é uma máquina transformável para fins totalmente diversos e que, na hipótese de ser transformada, continue funcionando com a mesma regularidade de antes" [Jung 1976].

A opção pela combinação das metodologias junguiana e Myers-Briggs busca, desta forma, e no contexto da presente pesquisa, elaborar um diagnóstico mais claro dessas disposições e nuances no nível individual [Faquin 2016]. Busca-se contribuir para um atendimento mais fiel das necessidades individuais sem que isso implique em um juízo de valor entre um bom e um ruim, um superior e um inferior. Adicionalmente, investiga-se caminhos para elevar a eficiência educacional e o atendimento dos profissionais recém-formados às recomendações curriculares (MEC/ACM) e às exigências do mercado de trabalho, ao mesmo tempo em que se busca preservar a diversidade de perfis e evitar quaisquer padronizações ou punições aos tipos psicológicos "não-adequados".

Exemplifica-se, na Tabela 2, como são delineadas as competências esperadas de profissionais em computação. Parte-se do princípio de que o aluno deve possuir uma série de habilidades para que tenha o domínio de uma competência. Essas habilidades são desenvolvidas ao longo das disciplinas cursadas, participação em projetos de pesquisa ou extensão, convivência com outros alunos, entre outros.

Tabela 2. Competências definidas para concluintes em cursos de computação

\begin{tabular}{|c|l|}
\hline $\begin{array}{c}\text { Instituição } \\
\text { definidora da } \\
\text { competência }\end{array}$ & \multicolumn{1}{c|}{ Competência } \\
\hline $\begin{array}{l}\text { ACM e IEEE } \\
\text { [ACM 2013] }\end{array}$ & $\begin{array}{l}\text { Competência para a solução de problemas: graduandos precisam saber } \\
\text { como aplicar o conhecimento que eles adquiriram na solução de } \\
\text { problemas reais, não apenas escrever código e mover bytes. Precisam } \\
\text { aprimorar sistemas utilizando avaliação quantitativa e qualitativa de sua } \\
\text { funcionalidade, utilidade e desempenho. Devem saber que existem } \\
\text { múltiplas soluções para um mesmo problema e que o critério de escolha } \\
\text { não é puramente técnico, já que pode exercer real impacto sobre a vida } \\
\text { de outras pessoas. } \\
\text { Comprometimento com uma vida de aprendizado: graduandos devem } \\
\text { ter em mente que o campo de computação dá voltas rapidamente e } \\
\text { devem possuir uma sólida formação que os permitam manter-se } \\
\text { encorajados a aprender à medida em que uma tecnologia avança. } \\
\text { Linguagens e tecnologias específicas mudam constantemente. } \\
\text { Graduandos precisam ter consciência de que precisarão continuar a }\end{array}$ \\
\hline
\end{tabular}




\begin{tabular}{|c|c|}
\hline & $\begin{array}{l}\text { aprender e a adaptar suas habilidades por toda a sua carreira. Devem ser } \\
\text { incentivados a obter constante desenvolvimento profissional, através de } \\
\text { treinamento, certificação ou obtenção de conhecimento sobre um } \\
\text { domínio restrito. }\end{array}$ \\
\hline $\begin{array}{l}\text { MEC } \\
\text { [Brasil 2012] }\end{array}$ & $\begin{array}{l}\text { Selecionar, configurar e gerenciar tecnologias da informação nas } \\
\text { organizações. } \\
\text { Atuar nas organizações públicas e privadas, para atingir os objetivos } \\
\text { organizacionais, usando as modernas tecnologias da informação. } \\
\text { Identificar oportunidades de mudanças e projetar soluções usando } \\
\text { tecnologias da informação nas organizações. } \\
\text { Comparar soluções alternativas para demandas organizacionais, } \\
\text { incluindo a análise de risco e integração das soluções propostas. } \\
\text { Gerenciar, manter e garantir a segurança dos sistemas de informação e } \\
\text { da infraestrutura de tecnologia da informação de uma organização. }\end{array}$ \\
\hline
\end{tabular}

\section{Metodologia e Estudo Experimental}

Para esta pesquisa, um estudo experimental foi aplicado em formandos e alunos de diferentes períodos de graduação em Bacharelado em Sistemas de Informação de uma instituição de ensino superior pública, totalizando 55 participantes. Uma exceção foi feita aos 36 recém ingressados em 2016 que, por ainda não possuírem notas em disciplinas concluídas, não participaram do estudo neste momento. Os dados relativos a alunos ingressantes em 2015, com apenas dois períodos finalizados e com poucas disciplinas concluídas, foram considerados para aferir o quadro de perfis psicológicos, não tendo sido possível tecer generalizações quanto ao seus rendimentos acadêmicos devido exatamente a esta escassez de informações. Igualmente foram excluídos do estudo alunos mais antigos e que apresentaram grande fragmentação das notas por razões como não-matrícula, desistência ou trancamento de matrícula em algum momento do curso. Desta forma, é apresentada aqui a análise dos perfis e rendimento acadêmico de 43 alunos, ou $78 \%$ do total. Estes 43 alunos estão distribuídos em 7 tipos psicológicos (dos 16 perfis possíveis pela metodologia junguiana e de MBTI) ou $43 \%$ do total.

Os participantes enviaram seus históricos acadêmicos completos e responderam a um questionário elaborado pelos pesquisadores deste trabalho baseado na metodologia de tipos psicológicos de Myers-Briggs e presente na obra "Tipos Psicológicos" de C. G. Jung para determinar um perfil psicológico predominante para cada participante. A opção por esta metodologia se deu pelo fato de ela ser a avaliação de perfil de personalidade mais difundida no mundo. Adicionalmente, há uma farta literatura que se utiliza desse quadro metodológico para aplicação em diversos ramos profissionais e segmentos da sociedade, o que favorece o diálogo comparativo entre pesquisas.

Os participantes acessaram o questionário disponibilizado no GoogleForms identificando-se com o número de matrícula. Todos eles foram previamente informados quanto ao tema e aos objetivos acadêmicos da pesquisa e assinaram um termo de livre consentimento com descrição da pesquisa e comprometimento de total confidencialidade dos dados fornecidos. Deste ponto em diante, o resultado dos questionários com os perfis psicológicos e as notas dos históricos acadêmicos foram organizados e analisados através de métodos estatísticos apropriados. 
Tabela 3. Descrição das funções psicológicas avaliadas

\begin{tabular}{|c|c|}
\hline $\begin{array}{l}\text { Extrovertido: preferem voltar sua } \\
\text { atenção para o mundo exterior das } \\
\text { pessoas e das atividades. Direcionam } \\
\text { sua energia e atenção para fora e } \\
\text { recebem energia da interação com } \\
\text { pessoas e da tomada de ação. }\end{array}$ & $\begin{array}{l}\text { Introvertido: gostam de focar em seu } \\
\text { próprio mundo de idéias e experiências. } \\
\text { Direcionam sua energia para dentro de si e } \\
\text { recebem energia da reflexão sobre seus } \\
\text { pensamentos, memórias e sentimentos. }\end{array}$ \\
\hline $\begin{array}{l}\text { Sentir: são aquelas que valorizam } \\
\text { informações reais e tangíveis: aquilo } \\
\text { que realmente acontece. Observam } \\
\text { coisas específicas ao seu redor e são } \\
\text { particularmente atentas a realidades } \\
\text { práticas. }\end{array}$ & $\begin{array}{l}\text { Intuir: consideram fatos dentro de } \\
\text { contextos grandes, atentando para seus } \\
\text { possíveis relacionamentos e conexões. } \\
\text { Buscam traçar padrões e enxergar novas } \\
\text { possibilidades. }\end{array}$ \\
\hline $\begin{array}{l}\text { Pensar: consideram em suas decisões } \\
\text { as consequências lógicas de uma } \\
\text { escolha ou ação. Mentalmente retiram a } \\
\text { si próprios de uma situação para } \\
\text { examinar seus prós e contras } \\
\text { objetivamente. São energizados pela } \\
\text { identificação, crítica, análise e solução } \\
\text { de um problema. Buscam atingir um } \\
\text { padrão ou princípio aplicável em } \\
\text { situações semelhantes. }\end{array}$ & $\begin{array}{l}\text { Sentimentalizar: consideram em suas } \\
\text { decisões o que é importante para elas e } \\
\text { para as outras pessoas envolvidas. } \\
\text { Colocam-se em uma situação para tomar } \\
\text { uma decisão. São energizadas ao auxiliar } \\
\text { outras pessoas e buscar nelas qualidades } \\
\text { para serem incentivadas. Criam harmonia } \\
\text { e tratam cada pessoa em sua singularidade. }\end{array}$ \\
\hline $\begin{array}{l}\text { Julgar: tendem a viver de forma } \\
\text { planejada e ordenada, buscando regular } \\
\text { e administrar suas vidas. Gostam de } \\
\text { tomar decisões, realizá-las e seguir seu } \\
\text { caminho. Suas vidas tendem a ser } \\
\text { estruturadas e organizadas e gostam de } \\
\text { ter as coisas resolvidas. Traçar planos e } \\
\text { cronogramas é importante para elas. } \\
\text { São energizadas por deixar as coisas }\end{array}$ & $\begin{array}{l}\text { Perceber: Gostam de viver de forma } \\
\text { flexível e espontânea, experimentando e } \\
\text { conhecendo a vida ao invés de controlá-la. } \\
\text { Decisões finais e planos detalhados } \\
\text { deixam-nas confinadas. Preferem } \\
\text { manter-se abertas a novas informações e } \\
\text { opções de última hora. São energizadas } \\
\text { pelos recursos disponíveis para se adaptar } \\
\text { às demandas de um momento. }\end{array}$ \\
\hline
\end{tabular}

O objetivo da aplicação do questionário é a identificação das funções psicológicas predominantes em cada um dos participantes. Foram respondidas 28 perguntas que buscam definir as quatro funções psicológicas predominantes no indivíduo dentre as seguintes dualidades: introvertido (I) ou extrovertido (E), sentir $(\mathrm{S})$ ou intuir $(\mathrm{N})$, pensar (T) ou sentimentalizar $(\mathrm{F})$, julgar $(\mathrm{J})$ ou perceber $(\mathrm{P})$. Estas dualidades sinalizam as seguintes características no indivíduo apresentadas na Tabela 3.

\section{Resultados Obtidos}

Essas quatro dualidades, em cruzamento, formam 16 perfis de personalidade distintos. Do preenchimento do questionário por um total de 55 participantes alguns dados se destacam, principalmente pela concentração de alunos em determinados perfis (Tabela 4). Obteve-se que $20,3 \%$ dos participantes concentraram-se apenas no perfil ISTJ (introvertido-sentir-pensar-julgar). Se for considerado apenas as funções STJ 
(sentir-pensar-julgar, na interseção da primeira coluna à esquerda e primeira e última linhas), $33 \%$ dos participantes aí se concentram. Nas funções ST (sentir-pensar, na primeira coluna à esquerda) estão reunidos $48,9 \%$ dos participantes e a função $\mathrm{S}$ (sentir, as duas colunas à esquerda) reúne $77,4 \%$ do total de pesquisados.

Tabela 4. Distribuição dos participantes avaliados pelos diferentes perfis psicológicos

\begin{tabular}{|c|c|c|c|}
\hline ISTJ & ISFJ & INFJ & INTJ \\
$20,3 \%$ & $3,3 \%$ & $1,6 \%$ & $5 \%$ \\
\hline ISTP & ISFP & INFP & INTP \\
$1,6 \%$ & $5 \%$ & $1,6 \%$ & $0 \%$ \\
\hline ESTP & ESFP & ENFP & ENTP \\
$13,5 \%$ & $11,8 \%$ & $5 \%$ & $5 \%$ \\
\hline ESTJ & ESFJ & ENFJ & ENTJ \\
$13,5 \%$ & $8,4 \%$ & $1,6 \%$ & $1,6 \%$ \\
\hline
\end{tabular}

A totalização das notas fornecidas pelos alunos e seu subsequente cruzamento com os perfis psicológicos abriu outros dados. A Tabela 5 apresenta a nota média obtida por alunos agrupados em 7 perfis psicológicos em disciplinas de línguas, gestão, matemáticas e informática do curso de Sistemas de Informação. Na última linha se encontra a nota média obtida por todos os alunos analisados na pesquisa. A função a ser analisada é a dualidade julgar-perceber, situada na última letra das siglas (J, nos quatro primeiros perfis, ou $\mathrm{P}$, nos três perfis seguintes). Alunos com função J-julgar predominante apresentaram desempenho médio em disciplinas de matemática e informática superior ao obtido por alunos com função P-perceber predominante. A nota média obtida pela turma ilustra com mais clareza esta divisão. O total de participantes obteve nota média 58,478 em matemáticas e 74,801 em informática. Este valor separa as notas médias: 1) todas as notas médias alcançadas por perfis com a função J-julgar encontram-se acima das notas medias de perfis com função P-perceber e acima da média da turma (exceto pela função INTJ em matemática, que encontra-se abaixo da média) e 2) todas as notas médias de perfis com a função P-perceber predominante encontram-se abaixo da nota média do total de alunos e das notas médias alcançadas por perfis com função P-perceber predominante, se consideradas as disciplinas dos núcleos de matemáticas e informática. A tabela 5 também destaca, em cinza claro, as notas médias mais altas e em cinza escuro as notas médias mais baixas em disciplinas aqui agrupadas por aera de conhecimento. As notas médias mais altas foram alcançadas por perfis com função J-julgar predominante e as notas médias mais baixas encontram-se em perfis com função P-perceber predominante.

Tabela 5. Notas médias de 7 perfis psicológicos e a média geral em disciplinas dos núcleos de línguas, gestão, matemática e informática

\begin{tabular}{|c|c|c|c|c|}
\hline Perfis\Áreas & Línguas & Gestão & Matemática & Informática \\
\hline INTJ & 84,525 & 82,122 & 58,192 & 82,786 \\
\hline ISTJ & 79,374 & 81,505 & 66,87 & 79,705 \\
\hline ESFJ & 79,888 & 79,94 & 62,409 & 77,893 \\
\hline ESTJ & 77,154 & 80,552 & 60,169 & 75,695 \\
\hline ESFP & 78,93 & 80,867 & 44,553 & 73,803 \\
\hline ESTP & 74,104 & 77,207 & 52,321 & 70,883 \\
\hline ISFP & 74,815 & 73,443 & 46,269 & 67,856 \\
\hline Total & 77,843 & 79,714 & 58,478 & 74,801 \\
\hline
\end{tabular}


$\mathrm{Na}$ figura 2, as notas médias encontradas em alunos com funções psicológicas J-julgar predominante (barras cinzas) é comparado com a nota média do total dos alunos participantes da pesquisa (barra preta). Observa-se que o desempenho em disciplinas do núcleo de línguas e gestão mantém-se predominantemente acima da média total. O mesmo padrão é encontrado quando observa-se a nota média destes perfis em disciplinas do núcleo de matemática e informática.

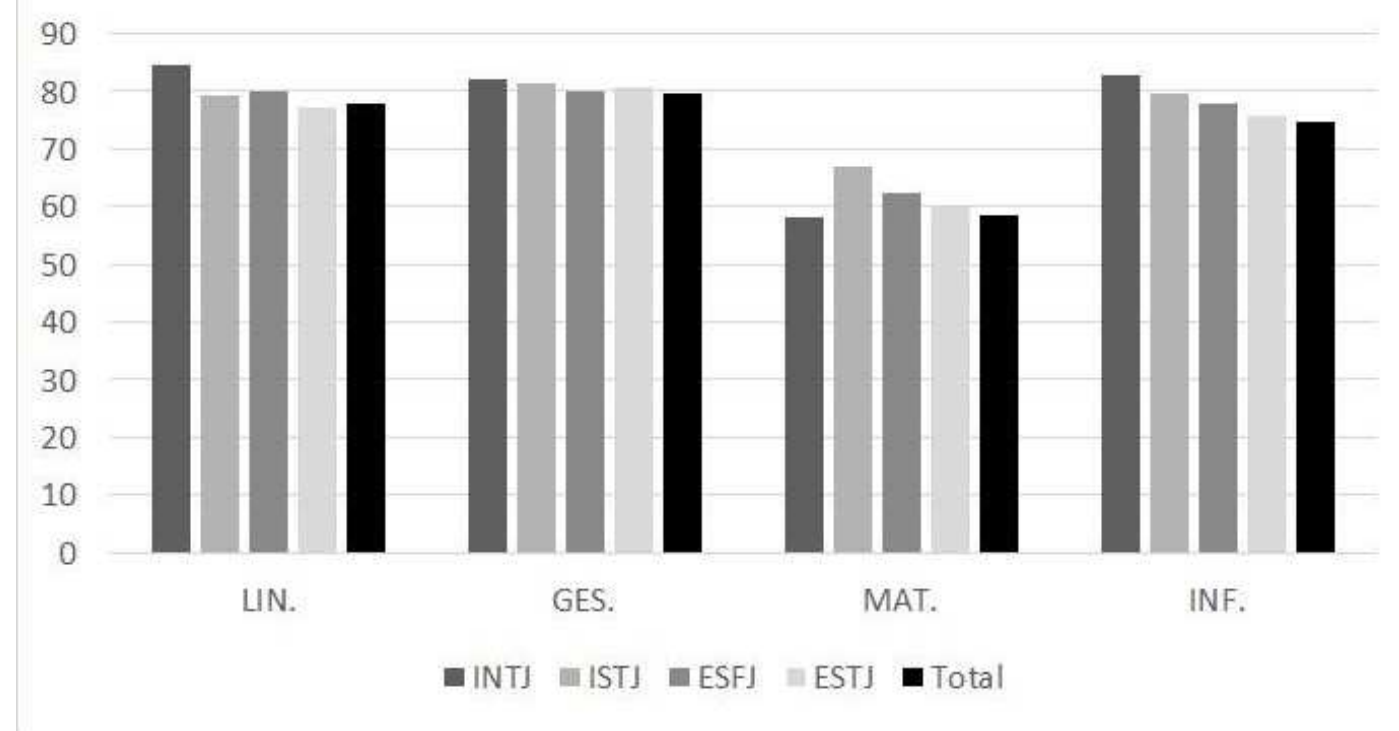

Figura 2. Notas médias dos perfis psicológicos com função J-julgar predominante em comparação com as notas médias do total de alunos do curso em disciplinas de línguas, administração, matemática e informática

Analogamente, na figura 3, as notas médias obtidas por alunos com funções psicológicas P-perceber predominante (barras cinzas) é comparado com a nota média do total dos alunos participantes da pesquisa (barra preta). Neste caso, percebe-se que o desempenho de alunos com estes perfis em disciplinas do núcleo de línguas e gestão oscila em torno da média obtida pelos alunos do curso, mantendo-se abaixo da média os perfis ESTP e ISFP. Quando observa-se o desempenho em disciplinas do núcleo de matemática e informática todas as notas médias obtidas por alunos com função P-perceber predominante mantém-se consistentemente abaixo da média. 


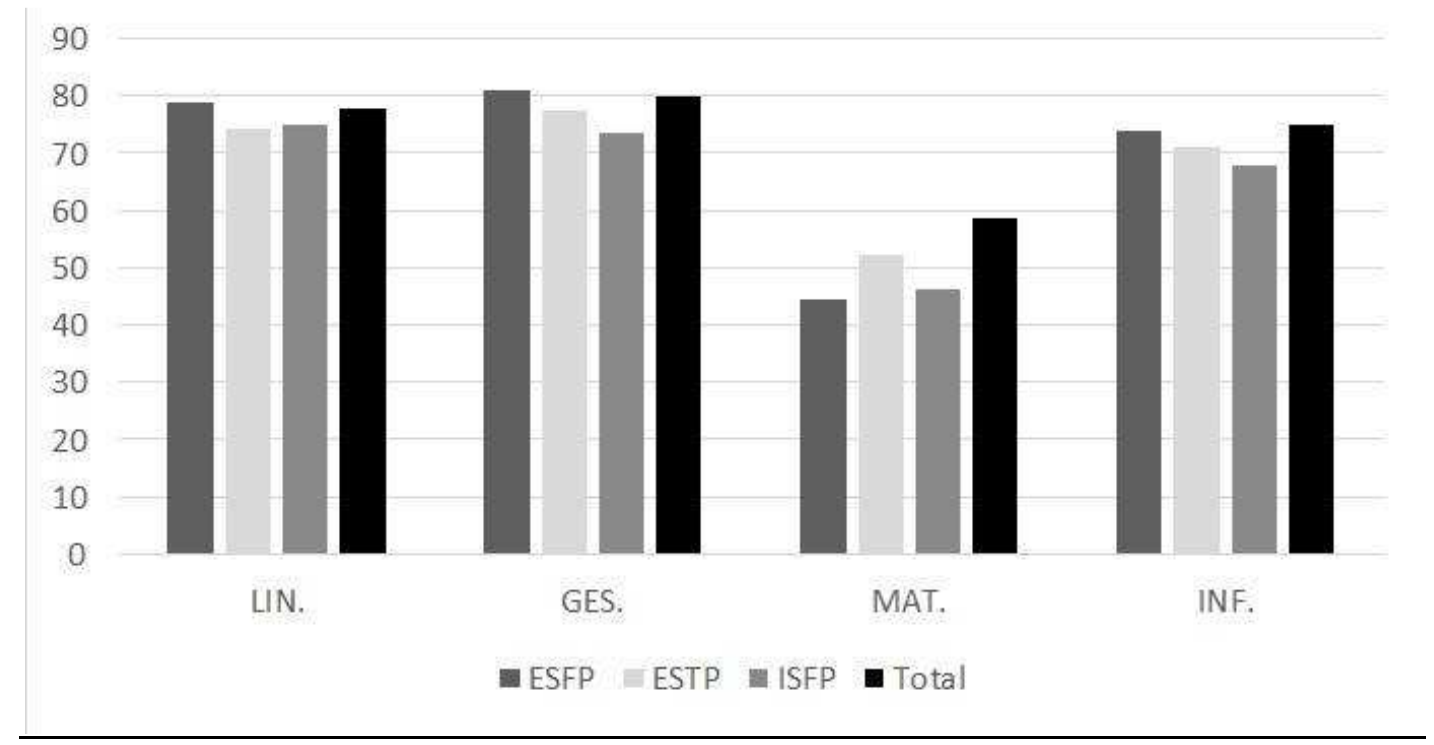

Figura 3. Notas médias dos perfis psicológicos com função P-perceber predominante em comparação com as notas médias do total de alunos do curso em disciplinas de línguas, administração, matemática e informática

Em seguida será analisada a relação entre dois perfis de personalidade, ESTP e ISTJ, e seus desempenhos acadêmicos de forma mais detalhada considerando-se não mais a nota média mas o desempenho de cada aluno. Estes dois perfis foram escolhidos por agruparem um maior número de alunos.

Na Figura 4 observa-se a distribuição das notas de 6 alunos de perfil ESTP, de função P-perceber predominante, portanto. Cada nota de um aluno em uma disciplina é representada por um círculo. Cada uma das linhas horizontais representa uma disciplina. As disciplinas foram agrupadas da seguinte forma: as do núcleo de línguas foram reunidas mais à esquerda (4 disciplinas, ou linhas, analisadas), as de administração logo em seguida (com 7 disciplinas), matemáticas (com 6 disciplinas) e informática (com 18 disciplinas). Ressalta-se que a função $\mathrm{P}$ desse perfil denota uma tendência à espontaneidade e flexibilidade quanto a prazos e planejamentos, como mostra a Tabela 3. Nesse caso, observa-se que nas disciplinas de línguas e gestão, o desempenho se mantém em sua totalidade acima de 60, mínimo para aprovação, com concentração entre 60 e 80. Quando desloca-se para disciplinas de matemática, mais à direita, percebe-se uma queda significativa no desempenho dos alunos. Além das reprovações recorrentes nesse caso, desempenhos muito inferiores a 40 (nota mínima exigida para que alunos tenham a chance de realizar uma prova final) como as aqui registradas, podem denotar abandono de disciplinas após as primeiras avaliações. Como informação adicional, ressalta-se que dos seis alunos, dois ingressaram em 2011 (5 anos de curso) e quatro em 2013 (três anos completos de curso), o que sugere que, além do baixo desempenho registrado, não se registrou aprovação em tentativas subsequentes em disciplinas de matemática.

Tem-se como hipótese que uma intervenção e orientação pedagógicas específica junto a alunos com esse perfil, considerando-se as características da função psicológica perceber descritas na Tabela 3, pode contribuir com uma melhora no desempenho desses 
alunos e na diminuição do risco de evasão do curso por desistência frente a dificuldades sobre como melhor lidar com uma área de conhecimento. Recomendações quanto a se buscar adquirir a habilidade de um maior planejamento de estudos, estímulo à resolução regular de listas de exercícios ou trabalho de apoio mais próximo junto a monitores, por exemplo, podem ser uma direção a ser considerada em conjunto por estudantes e professores na recuperação do desempenho acadêmico e do engajamento no curso. Nas disciplinas de informática observa-se uma concentração de alunos na faixa de desempenho entre 60 e 80 com alunos obtendo apenas o mínimo (60) para aprovação em muitas disciplinas, o que pode significar aprovação por prova final. De forma análoga, sugere-se a articulação das competências mínimas delineadas nos planos curriculares fornecidos pelo MEC e ACM com as características dessa função psicológica.

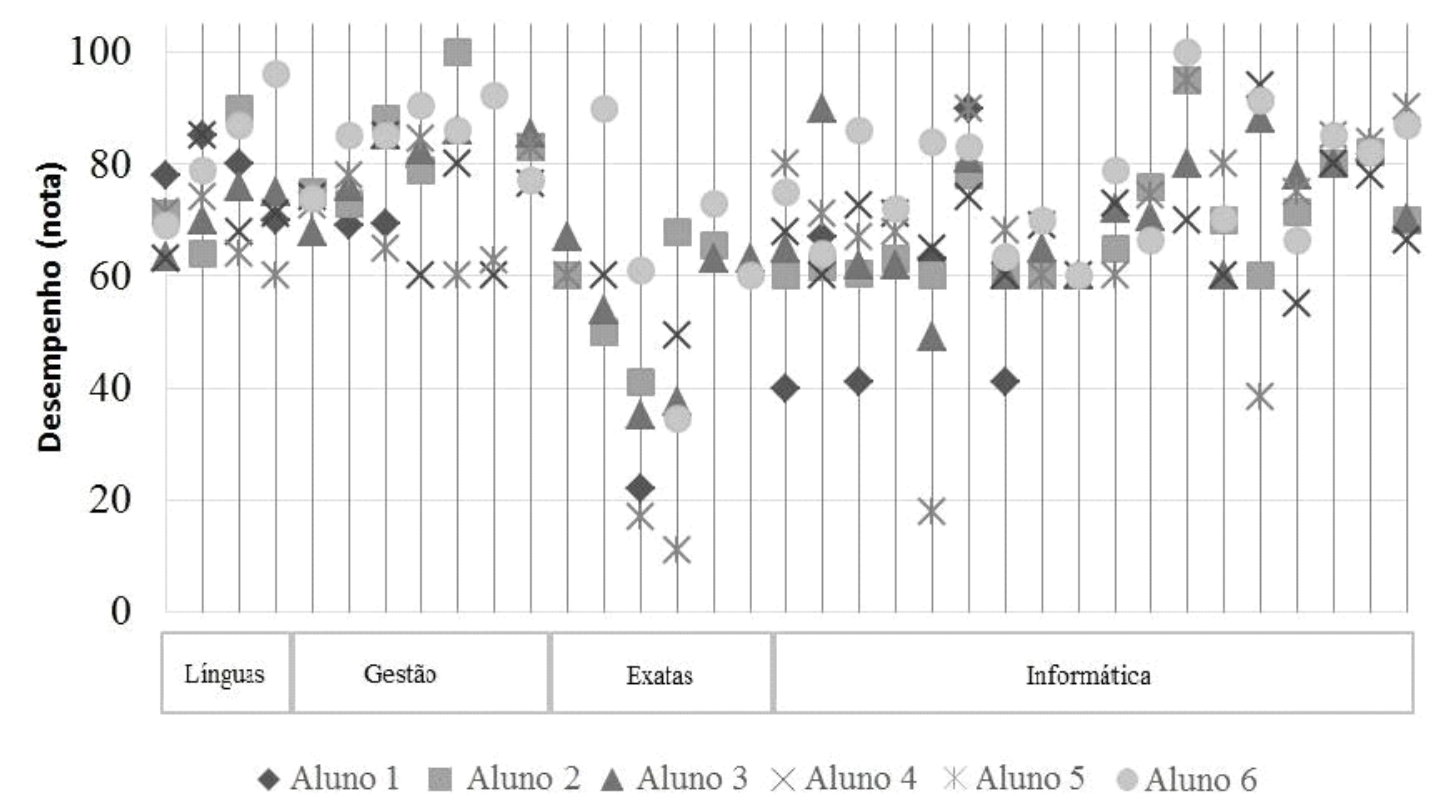

Figura 4. Distribuição do desempenho dos alunos de perfil ESTP entre disciplinas de línguas, administração, matemática e informática

Na Figura 5 observa-se a distribuição das notas de 7 alunos de perfil ISTJ. Esse perfil possui a função $\mathrm{J}$ de julgar, que denota maior familiaridade com planejamento e execução estruturados. Nesse sentido, a figura ilustra padrões de desempenho diferente da situação mostrada na figura 4. Nos alunos de perfil ISTJ observou-se uma concentração de alunos nas faixas superiores de desempenho em línguas e gestão. $\mathrm{Na}$ região de disciplinas de matemáticas, percebe-se uma maior consistência de alunos aprovados com boas notas, com poucos alunos populando a região de desistência (notas inferiores a 40). Destaca-se o fato de não haver, entre esse perfil, reprovações em disciplinas do núcleo de informática, com notas "flutuando" nas regiões de desempenho mais altas e com poucos casos de notas tocando a linha de 60 pontos, ao contrário da compressão nesse nível de desempenho observada no perfil ESTP. 


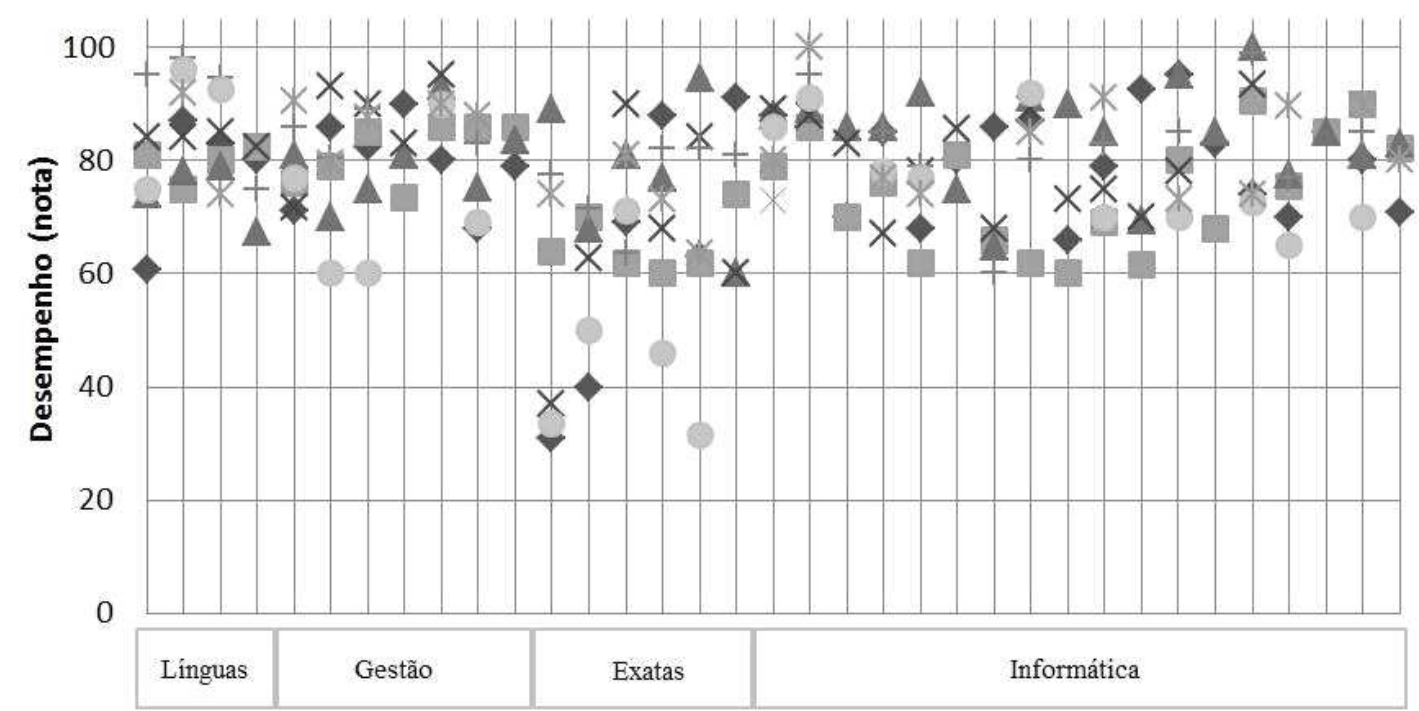

- Aluno 1 Aluno 2 A Aluno $3 \times$ Aluno $4+$ Aluno 5 Aluno $6 *$ Aluno 7

Figura 5. Distribuição do desempenho dos alunos de perfil ISTJ entre disciplinas de línguas, administração, matemática e informática

Na Figura 6 observa-se duas barras agrupadas (uma em tom cinza escuro e a outra em claro) que estão relacionadas, cada par, a uma disciplina. A barra de tom escuro representa a nota média alcançada pelos alunos de perfil ESTP. Pode se perceber padrão análogo ao observado na Figura 4 onde registra-se uma queda acentuada no desempenho dos alunos em disciplinas do núcleo de matemáticas. Neste núcleo, de 6 disciplinas analisadas, um desempenho superior a 60 foi registrado em apenas 2 disciplinas. Adicionalmente, a Figura 6 apresenta a barra cinza clara, que representa a porcentagem de alunos com este perfil que efetivamente se matricularam na respectiva disciplina. Observa-se que em 3 disciplinas do núcleo de línguas houve matrícula de 100\% dos alunos com perfil ESTP, 2 disciplinas de gestão alcançaram 100\% de matriculados com este perfil assim como em 6 disciplinas de matemática. Em informática observa-se uma boa adesão, com a taxa de matrícula se concentrando na faixa de $80 \%$ a $100 \%$. Em matemática, contrariamente, nenhuma disciplina contou com $100 \%$ de participação dos alunos com este perfil, o que pode demonstrar algum grau de relutância ou hesitação com relação a esta área. Para evitar maiores atrasos na conclusão do curso e o risco de evasão, recomenda-se ações que busquem estimular, nos alunos, a preocupação quanto a importância de se manter índices de matrícula nas disciplinas oferecidas em um dado período, qualquer que seja o núcleo. 


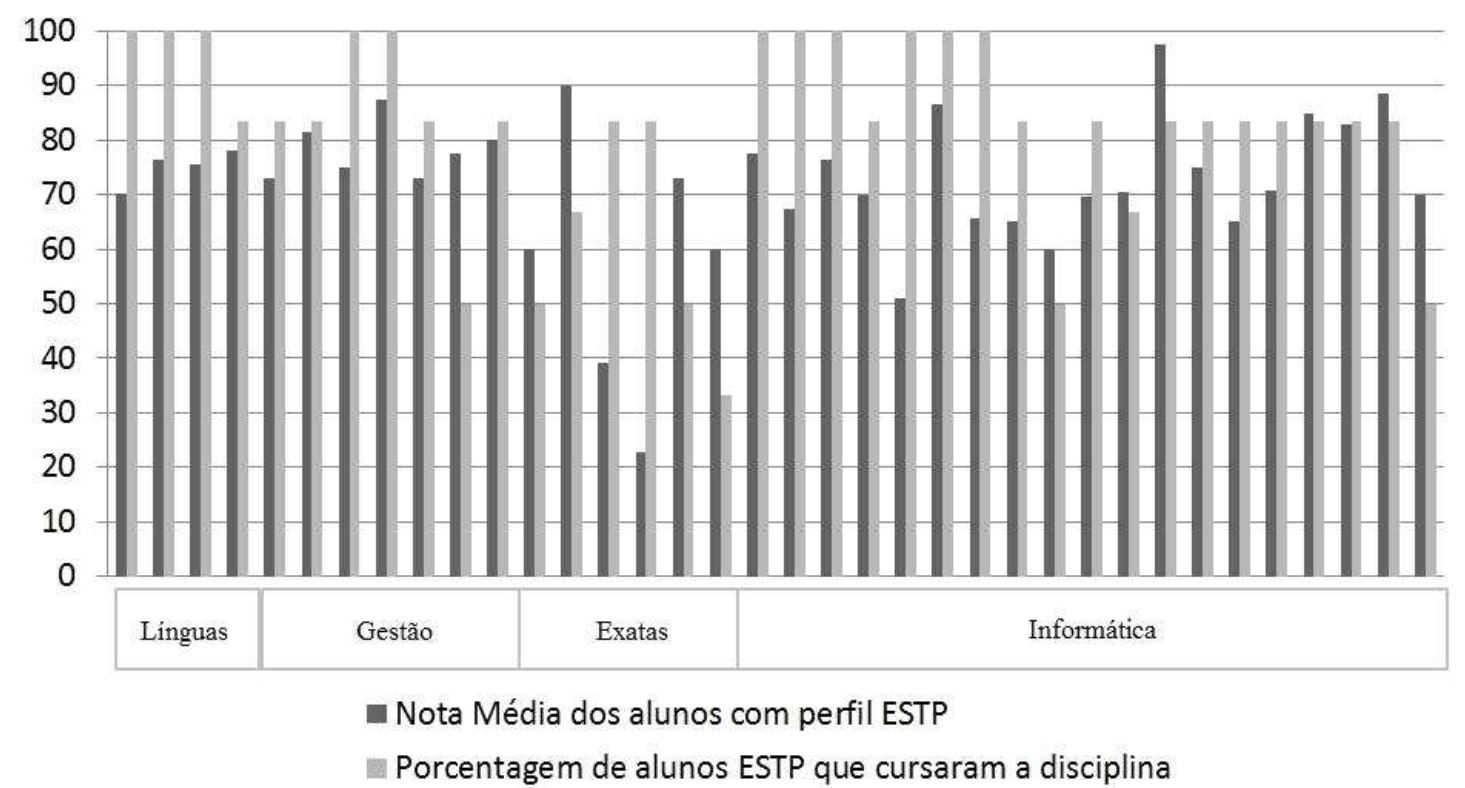

Figura 6. Notas médias alcançadas pelos alunos de perfil ESTP e suas participações nas respectivas disciplinas

$\mathrm{Na}$ figura 7 observa-se os mesmos dados relativos aos alunos de perfil ISTJ. Observa-se $100 \%$ de participação dos alunos deste perfil em 2 disciplinas do núcleo de línguas, 4 de gestão e 8 de informática. Em informática, observa-se uma grande oscilação de adesão entre $100 \%, 50 \%$ e até $40 \%$ de matriculados com este perfil. Em disciplinas do núcleo de matemática nota-se que em os alunos de perfil ISTJ mantiveram índices maiores de matricula em comparação ao perfil ESTP: 4 disciplinas com 100\% de matrículas de alunos com este perfil. Adicionalmente, os alunos ISTJ obtiveram igualmente um desempenho médio superior com notas médias predominantemente próximas ou acima da média.

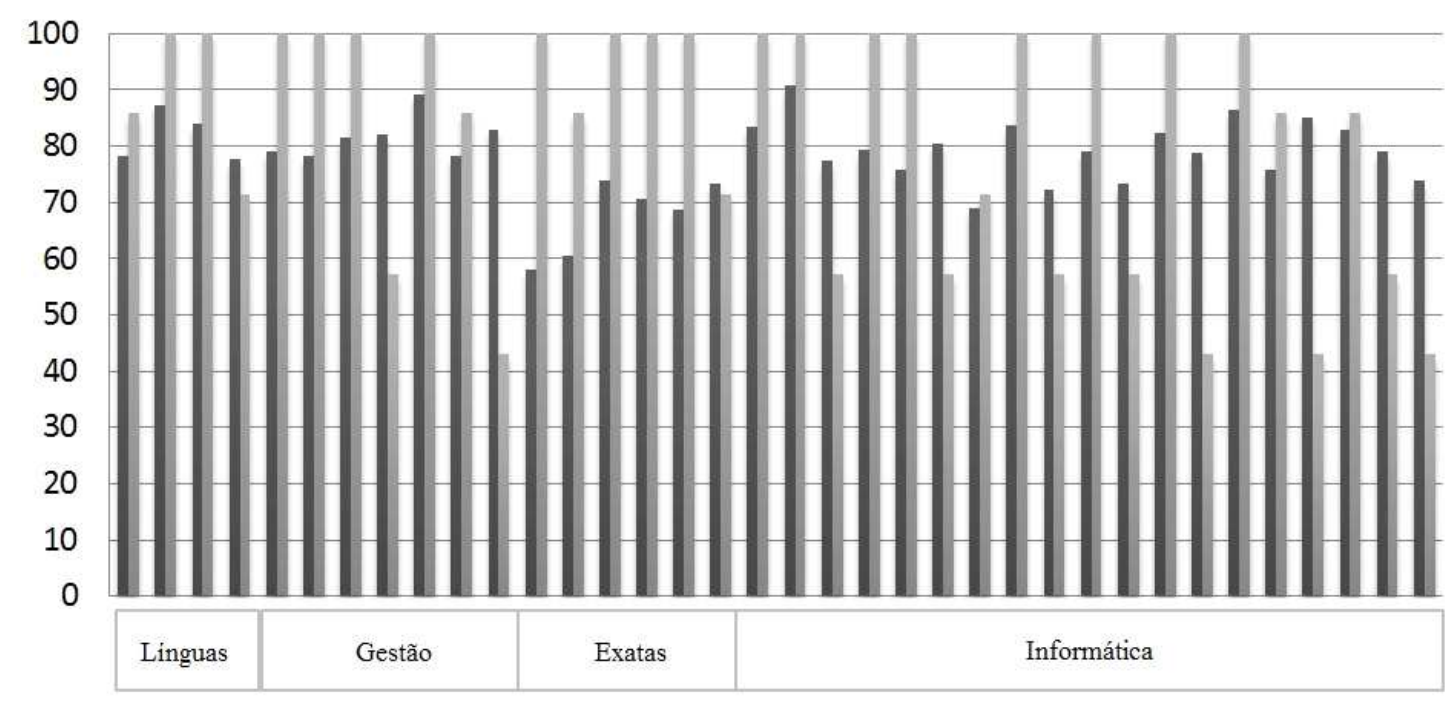

- Nota Média dos alunos com perfil ISTJ

- Porcentagem de alunos ISTJ que cursaram a disciplina 


\section{Figura 7. Notas médias alcançadas pelos alunos de perfil ISTJ e suas participações nas respectivas disciplinas}

\section{Considerações Finais e Trabalhos Futuros}

Buscou-se neste trabalho considerar como uma característica comportamental da personalidade de um indivíduo, ou de um grupo de indivíduos, pode exercer impacto sobre seus desempenhos acadêmicos. $O$ objetivo da investigação da relação entre perfil de personalidade e desempenho acadêmico é sugerir um caminho pelo qual os alunos podem identificar as habilidades que lhes são mais familiares e desenvolver aquelas que permanecem menos exploradas ao longo de sua trajetória no ensino superior. Conclui-se que alunos devem ser apresentados à discussão sobre habilidades desde o início de suas trajetórias acadêmicas e que estejam permanentemente familiarizados a respeito das competências essenciais para futuros profissionais da área: que sejam capazes de atuar em equipes auto-organizadas, distribuídas e aptos a se auto avaliar e de observar criticamente seu próprio comportamento.

É necessária a discussão e a proposição de ferramentas práticas para se incrementar o engajamento de alunos nos cursos de Sistemas de Informação através de uma abordagem pedagógica sensível às disposições naturais de suas personalidades. $\mathrm{O}$ desafio é elevar a eficiência educacional e o atendimento dos profissionais recém-formados às recomendações curriculares (MEC/ACM) e ao mesmo tempo preservar e valorizar a diversidade de perfis e mitigar a evasão de acadêmicos. O estudo aqui proposto não pretende engessar o indivíduo em um perfil ou comportamento. Busca-se fornecer bases mais sistemáticas para a aplicação de estratégias diversificadas que tenham por objetivo maior eficiência pedagógica e menor evasão de alunos. Pretende também contribuir como uma ferramenta complementar de aconselhamento que permita que estudantes ampliem seus leques de habilidades e transitem com mais naturalidade entre funções psicológicas diversas às suas. Adicionalmente, professores e estudantes podem subsidiar uma discussão antes oculta ou explorada intuitivamente.

Como trabalhos futuros sugere-se que o experimento seja expandido para e aplicado em outros cursos como Ciência da Computação, Engenharia da Computação e Engenharia de Software tanto na rede privada quanto na pública de ensino. Para fins de validação, sugere-se a aplicação do questionário a populações distintas, preferencialmente em outros cursos e regiões do país, e que o questionário seja analisado quanto à sua discricionariedade segundo a técnica de consistência interna de medida psicológica Alfa de Crombach [Maroco \& Garcia-Marques 2013]. A relação entre tipos psicológicos e desempenho acadêmico deve ser expandida para os outros perfis encontrados na amostra desta pesquisa.

\section{Agradecimentos}

Os autores agradecem à FAPEMIG e CNPq pelo apoio financeiro e ao IFSudesteMG Campus Juiz de Fora por acolher institucionalmente a presente pesquisa.

\section{Referências}

Amorim, G. (2015) "O Mercado de Profissionais de Tecnologia da Informação e Comunicação no Brasil: uma análise do período de 2006 a 2013”. Disponível em http://www.brasscom.org.br/brasscom/Portugues/download.php?cod=1775. Acesso em 
junho de 2016.

Ardis, M., Budgen, D., Hislop, G., Offutt, J., Sebern, M., \& Visser, W. (2014). Software Engineering 2014: Curriculum Guidelines for Undergraduate Degree Programs in Software Engineering. joint effort of the ACM and the IEEE-Computer Society.

Bourque, P., \& Farley, R. E. (2014). SWEBOK V3. 0. IEEE Computer Society.

Brasil. (2012). "Diretrizes Curriculares Nacionais para os cursos de graduação em Computação”. Brasília, Brasil.

Brasil. (2014) "Portaria Inep número 238, de 02 de junho de 2014. Publicada no Diário Oficial da União em 04 de junho de 2014."

Brasscom. (2016) "Guia de Funções de Tecnologia da Informação e Comunicação no Brasil". Disponível em http://brasscom.org.br/brasscom/upload/noticia/1463064783guia_de_funcoes_de_tic_v3 3.pdf. Acesso em junho de 2016.

Erol, S., Granitzer, M., Happ, S., Jantunen, S., Jennings, B., Johannesson, P. e Schmidt, R. (2010). "Combining BPM and social software: contradiction or chance?". Journal of software maintenance and evolution: research and practice, 22(6-7), 449-476.

Faquin, G. S., Falci, M. L. F., Araújo, M. A. P. (2016). "Uma Metodologia de Avaliação da Relação entre Perfis de Personalidade e Desempenho Acadêmico em Alunos de Sistemas de Informação”. XII Brazilian Symposium on Information Systems, 285-292.

Joint Task Force on Computing Curricula, Association for Computing Machinery (ACM) and IEEE Computer Society (2013). "Computer Science Curricula 2013: Curriculum Guidelines for Undergraduate Degree Programs in Computer Science". ACM New York, EUA.

Jung, C. G. (1976). "Tipos Psicológicos”. Zahar, Brasil.

Maroco, J. \& Garcia-Marques, T. (2013). "Qual a fiabilidade do alfa de Cronbach? Questões antigas e soluções modernas?". Laboratório de Psicologia, 4(1), 65-90.

Quenk, N. L. (2009). "Essentials of Myers-Briggs type indicator assessment”. John Wiley \& Sons

Topi, H., Karsten, H., Brown, S., Carvalho, J. A., Donnellan, B., Shen, J. e Thouin, M. (2015). Revising the MSIS Curriculum: Initial Report for Public Comments and Feedback.

Topi, H., Valacich, J. S., Wright, R. T., Kaiser, K. M., Nunamaker Jr, J. F., Sipior, J. C., \& De Vreede, G. J. (2010). Curriculum guidelines for undergraduate degree programs in information systems. ACM/AIS task force. 